\title{
Implementasi Pendidikan Pancasila Dalam Menumbuhkan Rasa Nasionalisme Generasi Muda di Era Digital
}

\author{
Ayu kartini ${ }^{1}$, Dinie Anggraeni Dewi ${ }^{2}$ \\ 1,2 Universitas Pendidikan Indonesia Kampus Cibiru, Indonesia \\ e-mail: ayu.kartini07@upi.edu
}

\begin{abstract}
Challenges in the current digital era cannot be avoided by all countries in the world, including Indonesia. By upholding the values of Pancasila Education and sticking to it as a guide in life. Indonesia will be able to maintain its national identity and existence. It aims to raise awareness of nationalism in the minds of today's young generation, in order to make them more resistant to the influence of today's increasingly rapid technology. Thus, the values of Pancasila education must be applied according to individual self-awareness. The development of this digital era makes the younger generation addicted by eliminating their identity. This digital development has several benefits in positive and negative impacts. The author aims to determine the application of Pancasila education learning in growing awareness of nationalism and Pancasila values as the younger generation in this digital era. This study uses qualitative research, the method used is to collect literature studies on Pancasila education to raise awareness of a sense of nationalism. The results of the study indicate that the implementation of Pancasila education must adhere to the values of Pancasila and the various impacts that affect the current state of the digital era, the younger generation is very important to raise awareness of nationalism with Pancasila values as a way of life. The development of this digital era, as the younger generation in acting or acting must be based on the values of Pancasila. The younger generation must prepare themselves to face the challenges of today's technological developments. Pancasila functions as a position on the basis of the state and upholds the values of Pancasila in everyday life.
\end{abstract}

Keywords: Pancasila Education, digital, young generation, and nationalism

\begin{abstract}
Abstrak: Tantangan di era digital saat ini tidak dapat dihindari oleh semua negara di dunia, termasuk negara Indonesia. Dengan menjunjung nilai-nilai Pendidikan Pancasila dan berpegang teguh sebagai pedoman dalam kehidupan, Indonesia akan mampu mempertahankan identitas nasionalnya dan eksistensinya. Hal ini bertujuan untuk menumbuhkan kesadaran nasionalisme dalam pikiran generasi muda saat ini, agar membuat mereka lebih tahan terhadap pengaruh teknologi sekarang yang semakin pesat. Dengan demikian, nilai-nilai pendidikan pancasila harus sudah diterapkan sesuai kesadaran diri individu. Perkembangan era digital ini membuat generasi muda kecanduan dengan menghilangkan jati dirinya. Perkembangan digital ini mempunyai beberapa manfaat dalam dampak positif dan dampak negatif. Penulis bertujuan untuk mengetahui penerapan pembelajaran pendidikan pancasila dalam menumbuhkan kesadaran nasionalisme dan nilai-nilai pacasila sebagai generasi muda diera digital ini. Penelitian ini menggunakan jenis penelitian kualitatif, metode yang digunakan dengan mengumpulkan studi literatur mengenai pendidikan pancasila untuk menumbuhkan kesadaran rasa nasionalisme. Hasil dari penelitian menunjukkan bahwa implementasi pendidikan pancasila harus berpegang teguh pada nilai-nilai sila pancasila dan adanya berbagai dampak yang memengaruhi keadaan diera digital saat ini, generasi muda sangat penting untuk menumbuhkan kesadaran nasionalisme dengan nilai pancasila sebagai pandangan hidup. Perkembangan era digital ini, sebagai generasi muda dalam bertingkah atau bersikap harus didasarkan nilai-nilai sila pancasila. Generasi muda harus
\end{abstract}


mempersiapkan diri untuk menghadapi tantangan pada perkembangan teknologi saat ini. Pancasila berfungsi sebagai kedudukan pada dasar negara dan menjunjung tinggi nilai sila pancasila dalam kehidupan sehari-hari.

Kata kunci : Pendidikan Pancasila, digital, generasi muda, dan nasionalisme

Copyright (c) 2021 The Authors. This is an open access article under the CC BY-SA 4.0 license (https://creativecommons.org/licenses/by-sa/4.0/)

\section{PENDAHULUAN}

Pendidikan merupakan jalan untuk menentukan arah kehidupan. Pendidikan sangat penting untuk memenuhi kebutuhan manusia agar dapat mengembangkan kualitas, minat bakat, dan potensi dalam diri setiap individu. Pendidikan mewujudkan anak bangsa yang memiliki kualitas dan memberikan konstribusi agar dapat menumbuhkan keunggulan bagi setiap negara. Pendidikan sangat bermutu dalam membangun nilai dan jiwa. Dengan adanya pendidikan, suatu bangsa seharusnya dapat menyikapi setiap permasalahan yang mereka hadapi baik masalah individu maupun di lingkungan masyarakat.

Permasalahan timbul menjadikan lemahnya semangat dan rasa nasionalisme pada para pemuda. Dengan adanya tantangan era digital atau perkembangan teknologi mengakibatkan nilai-nilai pendidikan pancasila pada generasi muda menjadi tidak kokoh dan mudah luntur kerena generasi muda sangat kurang dalam penerapan nilai-nilai pendidikan Pancasila. Generasi muda sangat rentan terhadap pengaruh perkembangan teknologi saat ini, sehingga dengan membangun nilai-nilai pancasila terhadap kehidupan sehari-harinya perlu persiapan yang matang, agar siap menghadapi tantangan perkembangan teknologi informasi dapat mengambil manfaat dampak positif dan menghindari dampak negatif dari era digital ini.

Populasi di Indonesia menurut data Badan Perencanaan Pembangunan Nasional (Bapenas) hingga tahun 2030 akan menimbulkan populasi yang akan dipegang oleh kalangan usia produktif sehingga generasi muda harus berperan aktif dan masa depan Indonesia ada di tangan kita, yang mulai beranjak dewasa serta memasuki tahun bonus demografi. Generasi muda harus mampu membawa Indonesia menuju kejayaaan. Diharapkan dengan adanya penerapan rasa nasionalisme, generasi muda menjadi lebih optimis bahwa Indonesia dapat menjadi bangsa yang lebih unggul. Generasi muda hampir mengabaikan nilai-nilai luhur bangsa. Perkembangan zaman sekarang banyak yang mengabaikan aturannya tidak mengikuti seperti zaman dulu, saat ini, dan masa depan generasi muda sangat 
berperan penting untuk menjaga kemajuan bangsa dengan rasa cinta tanah air, sebagai pondasi awal penggerak jalannya pembangunan nasional yang diharapkan. Misalnya, pada zaman saat ini kurangnya rasa empati dan nasionalisme sesama manusia dengan adanya perkembangan digital ini. Pada era digital ini mampu menciptakan dan bersaing dengan teknologi serta menerima tantangan yang dihadapi dengan rasa nasionalisme pada bangsa.

Berbagai akibat timbul dari permasalahan yang dihadapi pada era digital saat ini, rasa nasionalisme dan kebangsaan mulai memudar karena banyaknya generasi muda yang mementingkan diri individu dan kelompok tertentu pada perkembangan teknologi yang dialami saat ini. Dengan adanya ideologi yang dipegang negara Indonesia yaitu Pancasila, generasi muda harus mampu mengamalkan nilai-nilai pancasila membuktikan bahwa Pancasila sebagai pilar pemersatu bangsa dan pandangan hidup bangsa. Dari sejak kecil kita harus sudah diajarkan dasarnya ideologis Pancasila dengan pembelajaran yang diterapkan yaitu Pendidikan Pancasila .

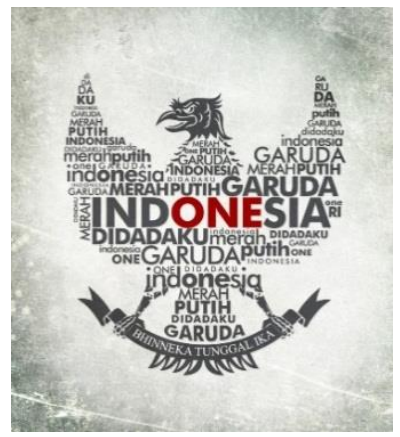

Gambar 1. Pancasila adalah pilar ideologis negara Indonesia

Sumber: https://www.freepnglogos.com/pics/logo-garuda-hd

Pendidikan Pancasila merupakan dasar negara serta ideologi bangsa Indonesia yang memiliki pedoman dan berpegang teguh pada nilai-nilai sila Pancasila. Pancasila harus menjadi patokan untuk menghadapi berbagai macam tantangan pada era digital ini. Dimana saat ini, perkembangan teknologi menjadi meningkat dan bersaing dengan manusia. Pancasila sangat berperan penting untuk menjaga kemajuan bangsa dan mempertahankan eksistensi kepribadian bangsa Indonesia di era digital ini. Oleh karena itu, perkembangan teknologi dapat bermanfaat bagi generasi muda dengan adanya beberapa dampak yang ditimbulkan. Generasi muda harus dapat meminimalisir penggunaan teknologi dan 
menggunakan teknologi sesuai kebutuhan serta dapat menyaring dengan baik dampak positif dan negatif dari perkembangan teknologi. Dampak positif yang diberikan adalah dengan menambah wawasan yang sangat luas dan mempererat hubungan dengan bangsa yang lainnya, sedangkan dampak negatif dari teknologi yaitu bisa merusak identitas dan moralitas yang dimiliki oleh bangsa Indonesia.

Hariyono (2014) menyatakan bangsa Indonesia selalu menempatkan posisi yang dominan dalam rumusan pancasila yaitu sebagai dasar negara dan persatuan bangsa Indonesia. Pancasila sangat relevan dalam mewujudkan kehidupan yang bermatabat. Pancasila merupakan cermin kehidupan bangsa Indonesia sehari-hari dapat dilihat pada multipersfektif. Hal tersebut diihat dari fungsi pancasila sebagai jiwa bangsa, pedoman, dan pandangan hidup bangsa Indonesia, serta sarana tujuan hidup yang harus berlandaskan Pancasila. Sebagai generasi muda harus setia kepada bangsa dan negara dengan mempelajari dan menghayati Pancasila sebagai filsafat negara. Pancasila menghadapai kemajuan teknologi harus memiliki kesadaran berdasarkan nilai-nilai Pancasila yang sudah ada. Meningkatanya rasa nasionalisme dalam masyarakat, bangsa dan negara haus tetap bertahan pada identitas bangsa tanpa harus menghilangkan jati diri bangsa Indonesia dan patuh kepada nilai-nilai luhur Pancasila ditengan perkembangan teknologi saat ini (Irhandayaningsih, 2017).

Maka dari itu, para generasi muda sebagai tujuan bangsa Indonesia diharapkan mampu memiliki rasa nasionalisme dengan berpedoman pada nilai norma Pancasila meski perkembangan teknologi di era digital saat ini sangat pesat. Dengan pedoman Pancasila diharapkan generasi muda mampu menyaring kembali rasa cinta tanah air dari pengaruh digital yang berkembang saat ini. Hal ini dapat mengetahui masalah yang terjadi akibat dari pudarnya semangat nasionalisme pada para pemuda di era digital ini, dan mengetahui pentingnya menumbuhkan rasa semangat nasionalisme bagi para pemuda dalam kehidupan berbangsa dan bernegara di era digital ini.

\section{METODE}

Metode Jenis penelitian ini merupakan Studi Literatur. Penelitian ini dilakukan secara kualitatif yaitu dengan mengkaji sumber-sumber yang terkait dengan Pancasila, rasa nasionalisme, generasi muda, dan perkembangan era digital 
ini sehingga dapat menumbuhkan generasi muda mengenai Pancasila milenial. Penelitian ini membahas tentang peran Pancasila agar generasi muda dapat menumbuhkan rasa nasionalisme pada negara sendiri. Penelitian ini bersifat kualitatif dan menggambarkan pokok persfektif dari implementasi nilai sila-sila Pancasila.

\section{HASIL DAN PEMBAHASAN}

Penelitian menunjukkan bahwa generasi muda dapat mengimplementasikan nilai-nilai sila Pancasila di sekolah dengan mengikuti pembelajaran pendidikan Pancasila. Generasi muda merupakan peran yang sangat penting dalam memajukan Indonesia dengan perkembangan teknologi saat ini. Proses pembelajaran pendidikan Pancasila dapat berfungsi sebagai kehidupan arah di masa depan dengan perkembangan teknologi yang merujuk kepada nilai sila Pancasila. Peran nilai pendidikan Pancasila dapat berbagai pengaruh dampak negatif dan positif. Secara etimologi, Pancasila berasal dari bahasa Sansekerta dan terdiri dari dua kata, Panca yaitu lima dan Sila yaitu dasar, asas, atau prinsip. Jadi Pancasila dapat diartikan sebagai lima dasar. Pancasila yaitu suatu dasar negara, ideologi negara, dan sebagai pandangan atau pedoman kehidupan bangsa. Pancasila harus kuat dan kokoh bagi setiap kehidupan bangsa, dan merupakan cerminan ideologi suatu bangsa agar dapat maju serta harus terikat berdasarkan nilai-nilai Pancasila di perkembangan era digital ini dalam berbagai bidang (Amir, S 2013). Dengan berpedoman pada nilainilai Pancasila sebagai pandangan hidup untuk membangun kemajuan bangsa dan diri tiap individu. Oleh sebab itu, Peran Pendidikan Pancasila dalam proses pembelajaran sebagai awal memperkenalkan kesadaran atau cita-cita moral yang menjiwai dan dijiwai bangsa dalam era digital ini.

Era digital adalah zaman yang berada dalam kondisi kehidupan yang mendukung adanya perkembangan teknologi agar lebih mudah menemukan informasi. Teknologi adalah alat sebagai sistem untuk melakukan pengembangan dan menyelesaikan permasalahan yang terjadi pada setiap kehidupan masyarakat, bangsa dan negara. Dalam hal ini, generasi muda harus mempunyai rasa nasionalisme dalam menumbuhkan kesadaran tiap individu pada perkembangan era digital. 


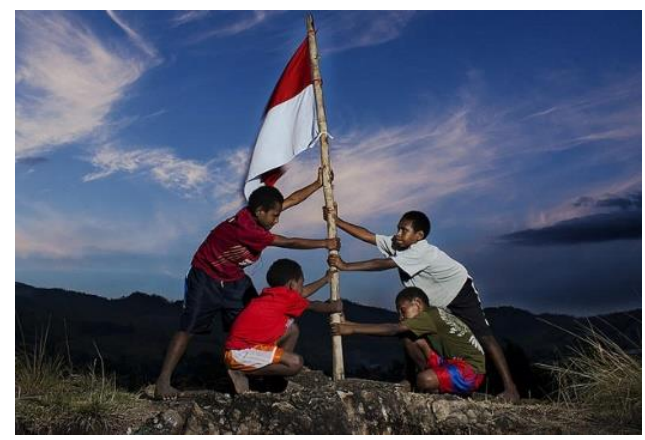

Gambar 2. memelihara semangat nasionalisme akan membuat generasi muda lebih tangguh terhadap pengaruh negatif di Era Digital sumber : https://www.google.com/amp/s/www.kompasiana.com/amp/arc_iw4n/5b7a49be677ffb2511369fa7 Ireaktualisasi-semangat-nasionalisme

Nasionalisme berasal dari kata 'nation' artinya bangsa. Nasionalisme selalu diartikan sebagai paham chauvinisme yaitu paham dengan mencintai bangsanya sendiri secara berlebihan. Paham ini bagi generasi muda tidak untuk dijadikan sebagai pemahaman dalam kehidupannya, pemuda harus mencintai tanah air Indonesia dengan tidak secara berlebihan mampu untuk menumbuhkan rasa nasionalisme agar tidak memudarnya semangat jiwa bangsa. Menurut UndangUndang No 40/2009 mengenai para pemuda atau generasi muda merupakan Setiap warga negara Indonesia yang memenuhi usia produktif yaitu 16-30 tahun. Generasi muda dapat dilihat dari sifat yang dimiliki dengan beranekaragam etnis, politik, ekonomi, dan bahasa. Para pemuda Indonesia belum memiliki wawasan nusantara, dan belum mengenal lebih mengenai tanah airnya, dari sabang saapai merauke banyaknya keanekaragaman didalamnya, hal ini merupakan generasi muda yang kurang mencintai tanah airnya sendiri yaitu Indonesia. Dengan perkembangan digital saat ini, generasi muda harus mampu bersaing dengan ketatnya teknologi saat ini.

Pancasila sejak awal sudah menempati sebagai dasar negara dan menjadi pandangan hidup bagi masyarakat, serta menjadikan pedoman dalam kehidupan bangsa dan negara. Pancasila mulai pudar eksistensinya dikalangan para pemuda. Maka dari itu, diharapkan kejayaan Pancasila akan muncul kembali dan para pemuda mulai sadar akan pentingnya rasa dan semangat nasionalisme. Dalam bidang ilmu pengetahuan, teknologi, agama, dan nilai budaya saling berkaitan memberikan kemajuan pada pemngembangan teknologi saat ini. Keterkaitan antara keempat hal tersebut dapat dijadikan dua kemungkinan, yaitu pertama sebagai 
pengembangan teknologi yang harus berdasarkan sikap human-religius dalam penggunaannya, karena posisinya yang harus selalu berdampingan dengan kebudayaan dan agama agar tidak menyalahgunakan teknologi. Kedua, teknologi berada pada posisi yang menempatkan agama dan budaya saling berkaitan dengan tukar pikiran.

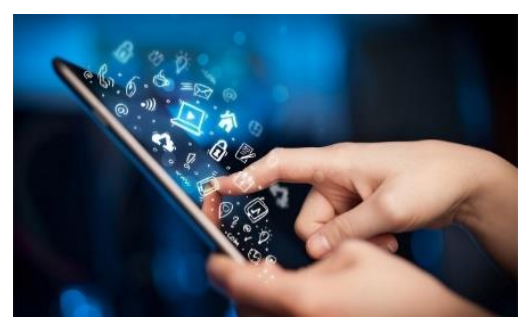

Gambar 3. Peran Pancasila sangat penting di Era Digital untuk di terapkan, agar tangguh dalam menghadapi tantangan teknologi

Sumber : https://www.google.com/amp/s/m.liputan6.com/amp/4187459/teknologi-informasi-dankomunikasi-jadi-kebutuhan-sehari-hari-di-masa-pandemi

Teknologi yang semakin pesat membuat generasi muda harus mampu mempertahankan nilai-nilai dasar pancasila dengan beriringan pada perkembangan era digital saat ini. Semangat patriotisme dan nasionalisme mulai memudar dikalangan generasi muda saat ini. Hal tersebut dapat dilihat dari beberapa generasi muda yang menganggap bahwa dengan adanya perkembangan teknologi semakin mudah untuk mengakses sesuatu dan mementingkan kepentingan individunya, tetapi hal ini terbalik dengan adanya teknologi generasi muda harus siap menghadapi semua tantangan yang terjadi. Generasi muda merupakan pilar bangsa yang mempunyai peran penting dalam mengahadapi berbagai macam tantangan. Masa depan bangsa tergantung dari sikap dan cara bertindak generasi muda.

Gambar 4. Generasi

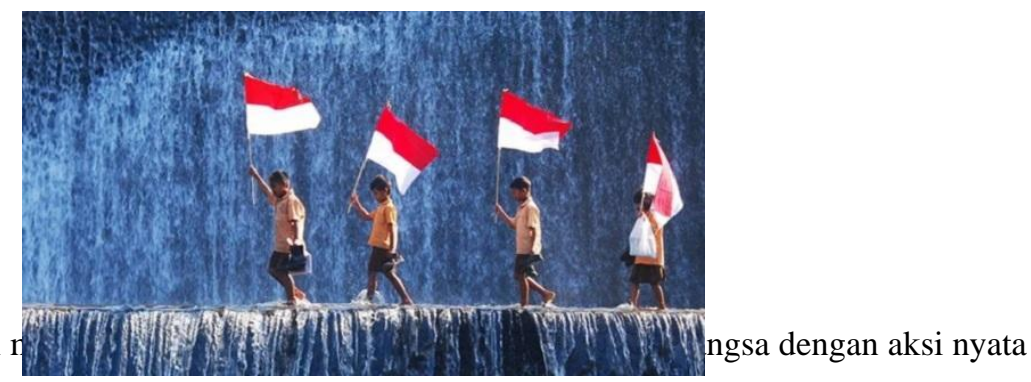

sumber : http://globalriau.com/nasional/membangun-kembali-semangat-nasionalisme-generasi-muda

Menjunjung nilai-nilai pancasila sebagai pandangan hidup setiap orang agar selalu diimplementasikan dalam kehidupan sehari-hari. Rasa nasionalisme harus tumbuh secara luas dikalangan generasi muda tidak nasionalisme yang sempit dan berdasarkan nilai-nilai Pancasila pada era digital saat ini. 
Pancasila merupakan ideologi negara Indonesia dengan berbagai macam nilai yang ada dalam bidangnya seperti nilai agama dan budaya. Pancasila menjadikan pedoman kehidupan dalam masyarakat, bangsa, dan bernegara. Rumusan Pancasila sebagai suatu sifat yang sangat penting dalam paradigma ilmu Perkembangan teknologi tidak terlepas dari nilai pancasila sebagai ideologi negara. Indonesia mempunyai budaya dan nilai religius yang berkembang dalam orientasi terarah. Maka dari itu, pancasila sebagai ideologi dengan berpegang teguh dalam kehidupan yang berkembang pada era digital ini. Para ahli harus mengetahui pengetahuan ilmunya tanpa menghilangkan nilai ideologi yang berasal dari masyarakatnya sendiri. Generasi muda sangat berpengaruh terhadap nilai-nilai pancasila dan sangat penting untuk menumbuhkan rasa nasionalisme dan patriotisme (Amrah, 2016). Hal inilah membuat para generasi muda harus mengobarkan rasa cinta tanah air dengan mengikuti nilai Pancasila (Widiyaningrum, 2019). Pancasila mempunyai lima sila dan satu diantaranya harus saling berkaitan menjiwai secara kesatuan yang utuh dan mempunyai makna dalam landasan bersikap dan bertindak. Di era digital ini banyak teknologi yang sudah berubah. Banyak teknologi dari luar yang masuk ke dalam, sebagai generasi muda tidak akan bisa menolaknya. Hal terpenting sebagai masyarakat Indonesia terutama generasi muda harus mampu memilah penggunaan teknologi dengan mementingkan individu serta mementingkan bangsa dan negaranya berdasarkan nilai pancasila (Sasongko , 2020).

Pada perkembangan teknologi, Pancasila harus dijadikan pondasi dalam kedudukannya di Indonesia. Kedudukan Pancasila sebagai pandangan hidup bangsa agar terarah dalam menjalani kehidupan. Nilai pada tiap sila Pancasila menjadi aplikatif dalam penggunaan implikasi ke dalam kehidupan sehari-hari. Dengan berpedoman Pancasila negara akan menjadi damai, aman, cerdas, dan sejahtera dalam kehidupan masyarakat, bangsa, dan negara tanpa melihat perbedaan SARA. Mengimplementasian nilai pancasila dalam kehidupan diri individu, membutuhkan proses pendekatan dalam memaknai nilai sila pancasila sebuah kesepakatan nasional dan nilai-nilainya dijunjung tinggi oleh semua golongan ( Sulasmono , 2019). Pancasila sebagai satu kesatuan yang utuh memiliki nilai sila pancasila yang tidak dapat berdiri sendiri tanpa sila lainnya. Pancasila dijadikan sebagai pandangan hidup dan dasar negara bagi Indonesia dalam kehidupan berbangsa dan bernegara. 
Pada generasi muda, nilai Pancasila semakin menurun karena adanya perkembangan era digital dan rasa cinta tanah air pun menurun ( Eta Yuni Lestari, 2019). Hal ini dilihat dari pandangan banyaknya generasi muda lebih mementingkan individu dibanding mementingkan sosial.

Dasar ideologi Pancasila merupakan peran pancasila yang menjadi sentral. Peran Pancasila dalam perkembangan teknologi mengakibatkan beberapa dampak, antara lain dampak positif dan negatif melalui nilai-nilai yang terkandung (Yudanegara, F. 2015). Secara positif dan negatif teknologi seperti sosial media bisa menjadi suatu inovasi perkembangan pembelajaran pada generasi muda saat ini. ( Fitri, S. 2017 ).

\section{Dampak Positif}

a. Media komunikasi

Perkembangan teknologi memiliki dampak yang sangat besar bagi kehidupan manusia. Jika dahulu manusia mempunyai keterbatasan jarak untuk dapat berkomunikasi dengan orang lain tidak dengan demikian.

b. Media pertukaran data

Perkembangan teknologi memudahkan seseorang untuk berbagi berbagai file dengan cepat, seperti film, musik, gambar dan data lainnya. Data tersebut dapat diakses dengan sangat cepat dan hanya membutuhkan beberapa langkah saja.

c. Media untuk hubungan Sosial

Media sosial merupakan salah satu hal yang tercipta dari adanya perkembangan teknologi ( Setiawan, D. 2014).

\section{Dampak Negatif}

Selain memberikan dampak positif, ternyata perkembangan teknologi informasi dapat memberikan dampak negatif bagi penggunanya. Hal tersebut muncul akibat dari penggunaan yang salah dan tidak bertanggung jawab. Saat ini banyak masyarakat yang lebih nyaman mempunyai teman dari dunia maya dari pada aktif pada kegiatan-kegiatan riil yang dapat memberikan kualitas hubungan pertemanan lebih intens dan kongkrit. Dalam Hal inilah Pancasila berfungsi sebagai kehidupan arah dimasa depan dengan berkembangnya teknologi ( Ratnaya, 2011). Pancasila dijadikan dasar negara dalam era digital saat ini, untuk kesejahteraan 
kehidupan masyarakat Indonesia. Pada perkembangan digital, sebagai generasi muda dalam bersikap harus didasarkan pada salah satu sila Pancasila yaitu kemanusiaan yang adil dan beradab. Pada dasarnya Pancasila adalah nilai, kerangka berfikir, dan sebagai dasar moralitas bagi perkembangan digital. Pancasila menunjukkan etika dalam pengembangan teknologi. Generasi muda harus mengimplementasikan nilai-nilai Pancasila dalam kehidupannya.

Merujuk kepada Pancasila Sila ke-1. Generasi muda diharapkan mampu mengimplementasikan pancasila dalam kehidupannya agar tidak mudah terpengaruh oleh apapun. Teknologi ditemukan serta dipertimbangkan juga tujuan dan akibat adanya perkembangan tersebut. Pada sila pertama ini manusia harus menjaga teknologi dan manfaatkannya dengan baik, karena generasi muda percaya bahwa apapun yang dikerjakan selalu dalam pengewasan Tuhan Yang Maha Esa.

Dengan merujuk kepada Sila ke-2 Pancasila, yaitu kemanusiaan yang adil dan beradap, diharapkan teknologi dijadikan sebagai proses dari terciptanya budaya manusia yang bermoral dan beradab. Maka dari itu, perkembangan teknologi harus berdasar pada hakikat dan bertujuan untuk mensejahterakan bangsa dan negara. Teknologi harus menjadi alat untuk meningkatkan harkat, martabat, dan bukan membuat manusia menjadi makhluk yang sombong akibat dari penggunaan teknologi. Khususnya bagi generasi muda, pada perkembangan teknologi, generasi muda harus dapat mempergunakan teknologi dengan sebijak mungkin. Generasi muda merupakan generasi bangsa. Apalagi di era digital saat ini, generasi muda tidak dapat dipisahkan dengan teknologi. Para generasi muda akan berhasil memajukan Indonesi menjadi satu, dengan kemampuan melakukan segalanya demi kepentingan bangsa dan negara. Dan mampu menciptakan rasa nasionalisme agar generasi muda siap menghadapi tantangan era digital saat ini, dan rasa persatuan bangsa Indonesia tercipta (Hermi Yanzi, et. al. 2019).

Di era digital ini, teknologi menjadi sangat melekat kepada semua kalangan masyarakat terutama generasi muda. Dengan mengimplementasikan Pancasila Sila ke-3 yaitu persatuan Indonesia, mampu memberikan rasa nasionalisme kepada para generasi muda bahwa rasa nasionalisme bangsa Indonesia dapat ditingkatkan di masa digital ini, akibat adanya penggunaan teknologi dengan maksimal, para pemuda dapat menggunakan teknologi secara baik dan benar, persatuan serta 
kesatuan bangsa dapat mewujudkan sifat saling terlibat satu sama lain sebab adanya faktor dari luar yang tidak dapat lepas dari kemajuan teknologi. Maka dari itu, perkembangan teknologi harus kuat dalam menjalin kesatuan dan persatuan agar dapat terjalin hubungan yang menuju internasional.

Implementasi dari Pancasila Sila ke-4, yaitu Kerakyatan yang dipimpin oleh hikmah kebijaksanaan dalam permusyawaratan/ perwakilan, dapat didasarkan pada adanya perkembangan teknologi secara demokrat di era digital. Hal ini menunjukkan setiap masyarakat Indonesia terutama generasi muda harus mampu mempunyai kebebasan dalam berpendapat dan berkembangnya teknologi secara terbuka, serta harus mempunyai sikap saling menghargai dan mampu mengkritik dan memberikan saran terhadap teknologi masa ini.

Implementasi dari Pancasila sila ke-5 yaitu, keadilan sosial bagi seluruh rakyat Indonesia. Keadilan ini berlaku pada perkembangan era digital ini dan rasa nasionalisme pada generasi muda. Sebagai generasi muda yang menggunakan teknologi diharapkan mampu berlaku secara adil harus mengutamakan kepentingan umum dalam kehidupan masyarakat, bangsa dan negara dari kepentingan individu berdasarkan nilai-nilai pancasila yang ada. Kelima sila pancasila ini menjadi pedoman yang berisi nilai-nilai sebagai kehidupan dan pengimplementasian dalam era digital saat ini.

\section{SIMPULAN}

\section{Kesimpulan}

Pendidikan Pancasila menjadi suatu pembelajaran dimana harus berpegang pada lima sila dan harus saling berkaitan menjiwai secara kesatuan yang utuh dan mempunyai makna dalam landasan bersikap dan bertindak. Di era digital ini banyak teknologi yang sudah berubah. Sebagai masyarakat Indonesia terutama generasi muda harus dapat memilah penggunaan teknologi baik dalam kepentingan individu atau kepentingan bangsa dan negaranya berdasarkan Pancasila.

Peran Pancasila sebagai dasar negara sangat krusial bagi perkembangan teknologi di Indonesia. Perkembangan digital saat ini, harus disertai dengan peran aktif para generasi muda berdasarkan nilai-nilai pancasila. Peran penting generasi muda berpengaruh pada kemajuan bangsa dan negara dengan berpegang teguh pada pancasila. Dengan menerapkan nilai-nilai pancasila pada generasi muda diharapkan 
mampu menumbuhkan rasa nasionalisme pada tiap individu agar siap dalam menhadapi tantangan perkembangan teknologi dan dapat mensejahterakan kesatuan bangsa dan negara.

Pancasila telah dijadikan dasar negara dalam era digital saat ini, untuk kesejahteraan kehidupan masyarakat Indonesia. Perkembangan digital saat ini, diharapkan generasi muda dalam bertingkah atau bersikap harus didasarkan pada sila kemanusiaan yang adil dan beradab dan berdasarkan pada nilai sila pancasila yang lainnya. Generasi muda harus mempersiapkan diri untuk menghadapi tantangan globalisasi saat ini. Pancasila berfungsi sebagai dasar negara dan menjunjung tinggi nilai-nilai yang terkandung. Untuk memperdalam pengetahuan mengenai peran Pancasila dalam menumbuhkan rasa nasionalisme pada Generasi Muda di Era Digital, generasi muda dapat menjalankan misinya sebagai pelaku utama dalam menumbuhkan rasa nasionalisme di era saat ini.

\section{Saran}

Berdasarkan hasil penelitian terdapat beberapa saran yang diperoleh sebagai berikut:

1. Penelitian dapat menggunakan pendekatan lainnya dengan memberikan dampak yang positif dan terjadi perbaikan dalam proses pembelajaran kedepannya.

2. Dalam pembelajaran pendidikan Pancasila lebih mengembangkan pembelajarannya dengan didukung oleh bahan ajar sehingga lebih menarik.

\section{DAFTAR RUJUKAN}

Amir, S. (2013). Pancasila As Integration Philosophy of Education and National Character. International Journal of Scientific \& Technology Research. Volume 2, Issue 1, January 2013.

Amrah. (2016). Mengulik Pengembangan Nasionalisme Generasi Muda Di Era Globalisasi. Jurnal Publikasi Pendidikan, 90-97. Diakses dari : https://ojs.unm.ac.id/pubpend/article/view/2094/1047

Eta Yuni Lestari, M. J. (2019). Menumbuhkan Kesadaran Nasionalisme Generasi

Muda Di Era Globalisasi Melalui Penerapan Nilai-Nilai Pancasila. Adil 
Indonesia Jurnal, 1 (1). 20-27. Diakses dari : http://jurnal.unw.ac.id:1254/index.php/AIJ/article/view/139/133.

Fitri, S. (2017). Dampak Positif Dan Negatif Sosial Mediaterhadap Perubahan Sosial Anak. Jurnal Kajian Penelitian Pendidikan dan Pembelajaran , 118123. Diakses dari :https://core.ac.uk/download/pdf/300094824.pdf Hariyono. (2014). Ideologi Pancasila Progresif Nasionalisme Indonesia. Malang : Intans Publishing.

Hermi Yanzi, Adha muhammad, dkk. (2019). Urgensi Nilai-Nilai Pancasila Sebagai Dasar Pengembangan Iptek Untuk Merespon Revolusi Industri 4.0. Iptek Untuk Merespon Revolusi Industri 4.0.

Irhandayaningsih. (2017). Peranan Pancasila Dalam Menumbuhkan Kesadaran Nasionalisme Generasi Muda Di Era Global . Fakultas Ilmu Budaya Universitas Diponegoro, 1-10. [online] Tersedia : https:// media.neliti.com/media/publications/5021-ID-peranan-pancasila-dalammenumbuhkan-kesadaran-nasionalisme-generasi-muda-di-era.pdf

Ratnaya, I. G. (2011). Dampak Negatif Perkembangan Teknologi . JPTK, UNDIKSHA, 17-28. (8) 1. Diakses dari : https://ejournal.undiksha.ac.id/index.php/JPTK/article/download/2890/239 $\underline{2}$

Sasongko .(2020). Di Era Digital, Perlu Strategi Tepat Kenalkan Pancasila ke Generasi Milenial: kompas.com. Diakses dari: https://nasional.kompas.com/read/2020/07/29/12263161/di-era-digitalperlu-strategi-tepat-kenalkan-pancasila-ke-generasi-milenial?page=all

Setiawan, D. (2014). Dampak Perkembangan Teknologi Informasi dan Komunikasi Terhadap Budaya Impact of Information Technology Development and Communication on Culture. SIMBOLIKA, 62-72. (4)1. Diakses dari: https://ojs.uma.ac.id/index.php/simbolika/article/view/1474/1441.

Sulasmono. (2019). Peluang Revitalisasi Nilai Nilai Pancasila Dalam Kehidupan Berbangsa Dan Bernegara. Jurnal Satya Widya, 75-85. Diakses dari : https://ejournal.uksw.edu/satyawidya/article/view/2392

Undang-Undang Republik Indonesia Nomor 40 Tahun 2009 tentang para pemuda atau generasi muda. 
418 | Jurnal Pendidikan dan Kewirausahaan Vol. 9 No. 22021

Widiyaningrum, (2019). Menumbuhkan Nilai Kesadaran Pancasila Di Kalangan Generasi Muda: Kajian Teoritis. Jurnal JISIPOL, 69-79. (3) 3. Diakses dari : http://ejournal.unibba.ac.id/index.php/jisipol/article/view/179/168

Yudanegara, F. (2015). Pancasila Sebagai Filter Pengaruh Globalisasi Terhadap Nilai-Nilai Nasionalisme. Jurnal Ilmu Administrasi CENDEKIA. Diakses dari: http://www.jurnal.unma.ac.id/index.php/JC/article/view/153/0 